\title{
Perceived Health Status: Is Obesity Perceived as a Risk Factor and Disease?
}

\author{
Tommy L.S. Visscher ${ }^{a, b, c}$ Jeroen Lakervelda, d Nanna Olsen ${ }^{a, e}$ \\ Leanne Küpers ${ }^{a, f}$ Sofia Ramalho ${ }^{a, g}$ Laura Keaver ${ }^{a, h} \quad$ Christina Brei ${ }^{a, i}$ \\ Jan-Inge Bjune ${ }^{a, j, k}$ Silvia Ezquerro ${ }^{a, l} \quad$ Volkan Yumuk ${ }^{a, m}$ \\ aEuropean Association for the Study of Obesity, New Investigators United, London, \\ UK; ${ }^{b}$ Research Centre for Healthy Cities, Windesheim University of Applied Sciences, \\ Zwolle, The Netherlands; ' ${ }^{C}$ European Association for the Study of Obesity, Patient Council \\ and Prevention and Public Health Taskforce, Founding Chair New Investigators United, \\ London, UK; ${ }^{\mathrm{d}}$ Department of Epidemiology and Biostatistics, EMGO Institute for Health \\ and Care Research, VU Medical Center, Amsterdam, The Netherlands; ${ }^{~}$ Research Unit for \\ Dietary Studies at the Parker Institute, Bispebjerg and Frederiksberg Hospital, the Capital \\ Region, Copenhagen, Denmark; ${ }^{f} \mathrm{MRC}$ Integrative Epidemiology Unit, University of Bristol, \\ Bristol, UK; ${ }^{9}$ School of Psychology, University of Minho, Braga, Portugal; ${ }^{\text {h Department of }}$ \\ Life Sciences, Institute of Technology Sligo, Sligo, Ireland; 'Else Körner-Fresenius-Center \\ for Nutritional Medicine, Klinikum rechts der Isar, Technische Universität München, \\ Munich, Germany; ${ }^{j}$ Hormone Laboratory, Haukeland University Hospital, Bergen, Norway; \\ kDepartment of Clinical Science K2 and KG Jebsen Center for Diabetes Research, University \\ of Bergen, Bergen, Norway; 'Metabolic Research Laboratory, Clínica Universidad de \\ Navarra, CIBEROBN, Pamplona, Spain; mIstanbul University Cerrahpasa Medical Faculty, \\ Division of Endocrinology, Metabolism and Diabetes, Istanbul, Turkey
}

\section{Key Words}

Determinants · Environment · Health promotion · Obesity · Perception

\begin{abstract}
One might expect that a perception of obesity being a risk factor and disease, contributes to effective obesity prevention and management strategies. However, obesity rates continue to increase worldwide. The question arises whether obesity is truly perceived as a risk factor and a disease. This paper aims at describing perception of obesity as risk factor and disease among individuals seeking care, individuals not seeking care, the society, and different professionals having a role in the field of obesity. The paper is a reflection of the lecture on the topic that was given at the EASO's New Investigators United's Summer School 2016 in Portugal and the discussion with the new investigators and other senior speakers. Individual obese patients seeking help are very much aware of obesity being a risk factor and disease, but perceptions regarding obesity seem to be flawed among those who do not seek help for obesity. Also, misperceptions regarding obesity play a role at different levels, including society, different
\end{abstract}


Visscher et al.: Perceived Health Status: Is Obesity Perceived as a Risk Factor and Disease?

political levels, the fields of health care and social work, prevention organizations, and the food and marketing industry. The food and marketing industry has an enormous role in changing perceptions by the society and policy makers. Obesity rates will continue to increase as long as individuals, the society, and professionals at different levels have false interpretations of the severity of obesity. Severe action is needed against those who are playing a role in maintaining false perceptions of obesity as a risk factor and disease.

(C) 2017 The Author(s)

Published by S. Karger GmbH, Freiburg

Evidence is clearly showing the enormous health, social and economic impact of obesity on individuals and societies $[1,2]$. To date, obesity ranks third in terms of worldwide economic burden after smoking as well as armed violence, war and terrorism [3]. The World Health Organization (WHO) has defined obesity as a disease (ICD-10: E66.0-E66.9) [4]. Obesity is associated with several forms of cancer, chronic conditions such as cardiovascular diseases and type 2 diabetes as well as several musculoskeletal disorders, and has an enormous direct impact on quality of life [1]. Obesity has also consequences for psychological health [5], and stigmatization against obese people is highly prevalent [6].

'Perception' is an important determinant for behavior or action in the field of health promotion [7]. One might expect that a perception among individuals, society, and professionals at different levels (policy, health care and social work, public health and prevention, schools etc.) of obesity being a risk factor and disease contributes to effective obesity prevention and management strategies. However, obesity rates continue to increase worldwide [8]. The question arises whether obesity is truly perceived as a risk factor and a disease. This paper aims at describing perception of obesity as risk factor and disease among individuals seeking care, individuals not seeking care, the society, and different professionals having a role in the field of obesity. The paper is a reflection of the lecture on the topic that was given at the EASO's New Investigators United's Summer School 2016 in Portugal and the discussion with the new investigators and other senior speakers.

Several health behavior theory models present perception as an important individuallevel concept in explaining behavior and choices [7]. If someone perceives a condition as a severe condition or as a severe risk, it is more likely that the individual becomes active to counteract the condition, as described in the Health Belief Model [9]. A person's perception or expectation regarding the consequences of action against a condition is an important predictor of the person's action, according to the Social-Cognitive Theory [10]. Likewise, a person's perception regarding the social pressure towards and norms regarding a condition or actions against the condition is a strong predictor of the person's action, according to the Theory of Planned Behavior [11].

Individual obese patients seeking help are very much aware of obesity being a disease and of the risks associated with obesity [6, 12-14]. Although obese patients have been reported to fail recognizing obesity as a risk factor for cancer [15], obese persons seeking help do perceive obesity as a social burden and as a risk factor for developing chronic conditions such as cardiovascular diseases and type 2 diabetes mellitus $[6,12,13]$. Burns et al. [16] have even reported that perceived health status is more strongly associated with quality of life than objective weight is. At the same time, perceptions regarding obesity among those who do not seek help for obesity seem to be flawed. Unfortunately, patients not seeking help outnumber patients who do seek help. Obese persons often underestimate their weight [17]. Even in overweight diabetic patients, weight status is often misperceived [18], even though we might think that the understanding of the role of obesity is well known among diabetic patients. Further, misperceptions are also severe in children and adolescents $[19,20]$, with 
Visscher et al.: Perceived Health Status: Is Obesity Perceived as a Risk Factor and Disease?

the prevalence of weight status misperception in children and adolescents being higher in the lower income families according to a US study [20]. In a study by McKee et al. [21], more than 2 out of 5 parents misperceived their child's body weight status. In fact, overweight/obese children and adolescents perceived themselves to have a healthy weight [22]. In parallel, healthy weight boys tend to perceive themselves as underweight [23]. In adolescence, lack of awareness of excess weight could be a cause for concern [22] since there is strong evidence that obesity tracks from adolescence into adulthood [24]. Perceived weight status and nutrition behaviors vary on their peers' perceptions about their weight status, but do not rely on what they think of their parents' perceptions [25]. Some adolescents reasoned that their parents were responsible for making healthy behavior possible, and at the same time that they could behave unhealthily, because they perceived themselves to be healthy [26]. Misperceptions regarding obesity and health behavior in adolescents could be problematic, because obese adolescents have the same comorbidities as obese adults and will suffer from these conditions 20-30 years longer than normal-weight counterparts, resulting in a great economic burden for modern societies [27].

So far, individual-level perceptions have been discussed. But, perceptions are likely to play a role at different levels including society, different political levels, the fields of health care and social work, prevention organizations, and the food and marketing industry. A misperception of the size of the obesity epidemic occurs when overweight, defined as BMI $\geq$ $25 \mathrm{~kg} / \mathrm{m}^{2}[28,29]$, becomes the common phenotype and when 'what is common becomes normal' [30]. To date, the overweight child is often perceived as the healthy, normal-weight child, while the healthy-weight child is perceived as skinny. The worldwide prevalence of overweight among adults is $40 \%$ in women and $38 \%$ in men. In the region of the Americas, $61 \%$ of both women and men are overweight. In the European and Eastern Mediterranean Regions, prevalence rates of overweight among women are higher than 50\% [28]. The USA is perhaps best known as the country with overweight prevalence rates being above 50\% [31], but other countries, e.g. Mexico, are rapidly taking over [32,33]. Also in Europe, obesity rates are likely to rival that of America in 2030 if prevention efforts are not further improved [34]. In an Irish study, overweight was projected to reach levels of $89 \%$ and $85 \%$ in males and females, respectively, by 2030 [35]. A true perception of still increasing obesity rates worldwide is needed for further action.

Amongst health care professionals and policy makers, obesity is sometimes being denied as disease. Such misperception of obesity does not contribute to strong action. When discussing perception of obesity as a risk factor or in association with ill health or disease, it is interesting to look how obesity fits in the definition of health. The WHO defines health as state of complete physical, mental, and social well-being, and not merely as the absence of disease [36]. Well, obesity is clearly associated with physical, mental and social impairments [1]. Canguilhem [37] and Huber et al. [38] defined health as the capacity of people to adapt to, respond to, or control life's challenges and changes. Using this definition of health, it makes even more sense to define and perceive obesity as ill health or disease. Obese people are facing difficulties to control and deal with the obesogenic environment [39]. Thus, according to different definitions of health, every denial of obesity being associated with disease is based on misperception.

It is not surprising that health care providers perceive or understand obesity as risk factor and disease only recently. It was only in 1988 when cardiovascular risk factors and diabetes risk factors were associated with obesity in Reaven's Banting lecture [40]. Disability as a consequence of obesity was described 25 years ago [41], quality of life 20 years ago [16], and the impact of obesity on musculoskeletal disorders started to gain wider recognition only 15 years ago [42]. The World Research Cancer Fund released a report on obesity and cancer only 10 years ago [43]. It will be a matter of time before all this knowledge reaches the 
Visscher et al.: Perceived Health Status: Is Obesity Perceived as a Risk Factor and Disease?

important textbooks of our students becoming the new professionals in the field of health and social work. Unfortunately, time is needed for evidence on how to best deal with false perceptions.

Obesity does not only have a medical but also a social impact. Stigmatization of obese people is a severe consequence of obesity [6]. And, again, perception is an important issue. For instance, one longitudinal study with 3,362 American school children visiting the 5th and 8th grade have shown that their teachers have the perception that obese students have lower abilities in math and reading and that they provide obese students with lower grades at school than nonobese peers, while having similar intelligence and achievement test scores [44]. Another study from the USA on more than 1,400 students from grade 8 in middle-school, community colleges, and university showed that obese students received significantly lower grades even when intelligence and achievement test scores were similar as those of normalweight students [45]. This leads to the conclusion that prejudice against overweight and obese students and false perceptions even exist among teachers [45].

Further, health policy makers and public health professionals are often being taught that prevention is not cost-effective, because diseases are being postponed, rather than prevented [46]. However, this is not likely the case with obesity prevention, as the number of unhealthy life-years is higher in obese individuals than in normal weight persons $[47,48]$. The Organisation for Economic Co-Operation and Development has calculated that the prevention of obesity is indeed likely to be cost-effective $[49,50]$. There is a body of evidence, although small, indicating favourble cost-effectiveness ratios in the areas of counseling of individuals at risk in a primary care setting, community-based counseling, school-based interventions, and interventions on the physical environment $[49,51]$. Universal prevention may be one of the key tools to slow down the increasing obesity prevalence rates. However, none of the studies included in previous reviews of obesity preventive interventions in children were restricted to normal-weight individuals [52], and hence leaves little evidence for how we can prevent the normal weight from developing obesity. In this regard, one of the main challenges in conducting universal prevention is to motivate individuals to participate in preventing efforts. Considering the Health Belief model, the combined levels of susceptibility and severity provides the level of motivation [9], and it may hence be argued that the individual perception of obesity as a health risk is vital to prevent development of obesity among the normal weight in the future. Improving the perception of the severity of obesity in terms of unhealthy life years and the perception of obesity prevention being cost-effective would really help the perception of health policy makers and public health professionals regarding the true impact of obesity and the true impact of obesity prevention efforts.

When discussing perceptions regarding obesity as risk factor and disease, it is also interesting to discuss both patients' and professionals' perceptions regarding obesity management. First of all, it is important to realize that health care professionals often inadequately perceive whether (young) children are overweight or obese [53]. Moreover, in the clinical setting misperception regarding obesity treatment occurs in both health professionals and individual patients, and their misperceptions do not necessarily match [12] and lead to flawed treatment and frustration [6]. When seeking care, different perceptions of health care professionals and patients are important barriers for successful management. Patients are often disappointed in the health care provider, because patients do not perceive to be taken seriously by the health care professional $[6,12,13]$, while the health care professional perceives the patient as not motivated $[12,13]$. In cases where obesity is named 'a disease' by the health care professional, the patient's perception could well be that the health care professional is going to treat the disease [13]. At the same time, while calling obesity a lifestyle factor, the health care professional's perception regarding the obese patient could well be that the patient has to solve the problem 'on her/his own' [12]. Likely, the perception of obesity and 
Visscher et al.: Perceived Health Status: Is Obesity Perceived as a Risk Factor and Disease?

the perception of successful strategies is not discussed well and unraveled in detail between patient and health care provider. Techniques such as motivational interviewing [54-56] and shared-decision making [57] seem promising strategies to discuss and interchange both patients' and professionals' perceptions regarding the obesity management strategy. Further, an issue may be that there is lack of perceived shared responsibility among health care professionals. Some may not be ready for the paradigm shift in which health care professionals have shared responsibility in a team of professionals that are all involved in the lifestyle changes of a patient who has become an active stakeholder in managing her/his disease [58]. Shared responsibility is important, because the problem of obesity is tackled from multiple angles, but it could also be a difficulty, in case none or few in the team perceive a shared responsibility.

Epidemiological misinterpretation of the data is another serious source of misperception of the severity of the obesity epidemic [8]. Misperception of the severity of the obesity epidemic among policy makers is an unwanted phenomenon in the combat against obesity, because policy makers need to perceive obesity as a severe burden, in order to change their policies. Hence, policy makers have a responsibility in weighing the severity of various and different challenges in society in order to be able to define priorities. The already discussed underestimations of self-reported body weight in the obese at individual level leads to underestimations of obesity rates in populations, and thus to misperceived perception of the severity of the size of the obesity epidemic [17]. Further, studies are suggesting that the obesity epidemic might be on its return, based on a plateau phase or even a decrease in the obesity prevalence, but the methodologies behind those studies are important to discuss [59]. Hence, presented decreases or stabilizations in the obesity epidemic are due to misinterpretation of the epidemiological data [8]. Whereas decreases in obesity are studied as decreases in obesity defined as BMI $\geq 30 \mathrm{~kg} / \mathrm{m}^{2}[28,29]$, a thorough look into the distributions of the BMI teaches us that BMI levels at the upper end of the distribution are still increasing and that the more severe forms of obesity are still becoming more prevalent [8]. Further, when waist circumference levels were included in the trend studies, the majority of studies showed increases in levels of waist circumference and abdominal obesity even when BMI $\geq 30 \mathrm{~kg} / \mathrm{m}^{2}$ did not increase [8]. Moreover, plateaus and decreases in BMI $\geq 30 \mathrm{~kg} / \mathrm{m}^{2}$ are seen in relatively short periods of time, that is less than 5 years, while we have seen such short-term decreases more often in the past. Those short-term decreases in the past have always been followed by further increases in the epidemic [8].

A major determinant for lack of action is the misperception of the obesogenicity of environments [60]. The food industry is one important barrier to the effective implementation of large-scale strategies to counteract the obesity epidemic [61], and it is still too easy to overconsume and to be inactive even though the role of the obesogenic environment is very clear now $[39,62]$. The lack of actions against the industry is reported to be due to low priority of the issue by politicians [63]. Also the food industry is likely to challenge governmental actions when they do occur [64]. The enormous availability in lifestyle hypes possibly increases this lack of actions even more as it becomes more and more unclear to policy makers which of these interventions best suit a society. 'Policy makers cannot see the wood for the trees' could be a result from this overload of knowledge on lifestyle interventions. While politicians may perceive the hypes of lifestyle interventions and actions by the industry as 'a lot is already being done by self-regulation,' the word 'hype' already implies that almost all of these hype interventions show short-term popularity and effect.

The marketing and lobby industry has an enormous role in changing perceptions by the society and policy makers. Important examples are increases in portion sizes [65-67] having an impact on consumers' choices [68], impact of package dimensions on perceptions of portion size [69], and advertisements targeting young children impacting their perceived 
Visscher et al.: Perceived Health Status: Is Obesity Perceived as a Risk Factor and Disease?

needs [70] while they are unaware of the persuasive content of advertising materials [71]. Although strong health policies with examples of introducing the ban of marketing of unhealthy food and the introduction of taxes on unhealthy choices [28, 72, 73] are described to be effective, populistic policy makers and governments find each other easily in agreeing that 'nudging' and forcing choices are unwanted phenomena in modern societies. Some argue that educating individuals is a better alternative than limiting portion size or banning kids marketing, to increase the people's choice. Indeed, it seems possible to increase the ability of adults to accurately estimate portion size through education or training [74]. But, budget and expertise behind these educational and health promotion programs are by far lower than the budget and expertise of the marketing industry. It is urgent to understand that the spending of billions by the marketing and food industry is meant to influence our choices and eating habits and should thus not be any longer be perceived as 'creating maximum consumers' choice'.

We conclude that individuals seeking help do perceive obesity as a risk factor and disease, but that, at the same time, upstream factors (industry, policy, and society) are still undermining the recognition of obesity as a risk factor and disease. Obesity rates will continue to increase as long as individuals, the society, and professionals at different levels of policy, health care, social work, schools, and prevention have false interpretations of the severity of obesity. Strong action is needed against those who are playing a role in maintaining false perceptions of obesity as a risk factor and disease.

\section{Disclosure Statement}

TLSV is an (unpaid) member of the EPODE International Network's scientific committee. The EPODE methodology includes public-private partnerships. His university receives budget for his participation in international EPODE meetings.

JL, NJO, LKK, SMR, LK, CB, JIB, SE and VY declare no conflicts of interest.

\section{References}

1 Visscher TLS, Seidell JC: The public health impact of obesity. Annu Rev Public Health 2001;22:355-375.

2 Frühbeck G, Toplak H, Woodward E, Yumuk V, Maislos M, Oppert JM; Executive Committee of the European Association for the Study of Obesity: Obesity: the gateway to ill health - an EASO position statement on a rising public health, clinical and scientific challenge in Europe. Obes Facts 2013;6:117-120.

3 Dobbs R, Sawers C, Thompson F, et al: Overcoming obesity: An initial economic analysis. McKinsey Global Institute. www.mckinsey.com/insights/economic_studies/how_the_world_could_better_fight_obesity (last accessed March 6, 2017).

4 International Statistical Classification of Diseases and Related Health Problems 10th Revision (ICD-10)-WHO Version, 2016. http://apps.who.int/classifications/icd10/browse/2016/en\#/E66 (last accessed February 1, 2017).

5 Avila C, Holloway AC, Hahn MK, Morrison KM, Restivo M, Anglin R, Taylor VH: An overview of links between obesity and mental health. Curr Obes Rep 2015;4:303-310.

6 European Association for the Study of Obesity: 2015 Milan Declaration: A Call to Action on Obesity. A Statement of the Members of the European Association for the Study of Obesity to EXPO 2015. London, UK, 2015. http:// gucdv1wwi8pslzdfpv7t0dk6.wpengine.netdna-cdn.com/wp-content/uploads/2015/06/EASO-Milan-Declaration-FINAL.pdf (last accessed February 1, 2017).

7 Brug Lechner L, Kremers S, Meertens R, Vries de H: Determinanten van gedrag; in Brug J, van Assema P, Lechner L (eds): Gezondhgeidsvoorlichting en gedragsverandering. Een planmatige aanpak. Van Gorcum, Open Universiteit, 2008.

8 Visscher TL, Heitmann BL, Rissanen A, Lahti-Koski M, Lissner L: A break in the obesity epidemic? Explained by biases or misinterpretation of the data? Int J Obes 2015;39:189-198.

9 Rosenstock IM: Why people use health services. Milbank Mem Fund Q 1966;44:94-127.

10 McAlister AL, Perry CL, Parcel GS: How individuals, environments, and health behaviors interact: Social Cognitive Theory; in Glanz K, Rimer BK, Viswanath K (eds): Health Behavior and Health Education: Theory, Research, and Practice, 4th ed. San Francisco, Jossey-Bass, 2008, pp 169-188. 
Visscher et al.: Perceived Health Status: Is Obesity Perceived as a Risk Factor and Disease?

11 Ajzen I: From intentions to actions: a theory of planned behavior; in Kuhl J, Beckman J (eds): Action-Control: From Cognition to Behavior. Heidelberg, Springer, 2010, pp 11-39.

12 Derksen RE, Brink-Melis WJ, Westerman MJ, ten Dam JJM, Seidell JC, Visscher TLS: Implementing a national integrated health care standard on obesity in a local primary care setting: focus groups give necessary insights. Fam Pract 2012;29(suppl 1):i177-i184.

13 Brink-Melis WJ, Derksen RE, Westerman MJ, Renders CM, Seidell JC, Visscher TLS: The local implementation of a chronic disease management model for childhood overweight and obesity. Obes Facts 2012;5:766-775.

14 Frühbeck G, Sbraccia P, Nisoli E, Woodward E, Yumuk V, Farpour-Lambert NJ, Halford JG, Toplak H, Carruba MO. 2015 Milan Declaration: a call to action on obesity - an EASO position statement on the occasion of the 2015 EXPO. Obes Facts 2016;9:296-298.

15 Soriano R, Ponce de León Rosales S, García R, García-García E, Méndez JP: High knowledge about obesity and its health risks, with the exception of cancer, among Mexican individuals. J Cancer Educ 2012;27:306-311.

16 Burns CM, Tijhuis MA, Seidell JC: The relationship between quality of life and perceived body weight and dieting history in Dutch men and women. Int J Obes 2001;25:1386-1392.

17 Visscher TLS, Viet AL, Kroesbergen IH, Seidell JC. Underreporting of BMI in adults and its effect on obesity prevalence estimations in the period 1998 to 2001. Obesity 2006;14:2054-63.

18 Mogre V, Nsoh JA, Wanaba P, Apala P: Demographic factors, weight management behaviours, receipt of healthcare professional's counselling and having knowledge in basic anthropometric measurements associated with underassessment of weight status in overweight and obese type 2 diabetes patients. Obes Res Clin Pract 2016;10:381-389.

19 Scholtens S, Brunekreef B, Visscher TLS, Smit HA, Kerkhof M, De Jongste JC, Gerritsen J, Wijga AH: Reported versus measured body weight and height of 4-year-old children and the prevalence of overweight. Eur J Public Health 2007;17:369-374.

20 Sarafrazi N, Hughes JP, Borrud L, Burt V, Paulose-Ram R: Data Brief 158: Perception of Weight Status in U.S. Children and Adolescents Aged 8-15 Years, 2005-2012.www.cdc.gov/nchs/data/databriefs/db158_table. pdf\#1 (last accessed February 1, 2017).

21 McKee C, Long L, Southward LH, Walker B, McCown J: The role of parental misperception of child's body weight in childhood obesity. J Pediatr Nurs 2016;31:196-203.

22 Jackson S, Johnson F, Croker H, Wardle J: Weight perceptions in a population sample of English adolescents: cause for celebration or concern? Int J Obes 2015;39:1488-1493.

23 Fredrickson J, Kremer P, Swinburn B, de Silva-Sanigorski A, McCabe M: Biopsychosocial correlates of weight status perception in Australian adolescents. Body Image 2013;10:552-557.

24 Nooyens ACJ, Koppes LLJ, Visscher TLS, Twisk JWR, Kemper HCG, Schuit AJ, Mechelen van W, Seidell JC: Adolescent skinfold thickness is a better predictor of adult high body fatness than body mass index: the Amsterdam growth and health longitudinal study. Am J Clin Nutr 2007;85:1533-1539.

25 Zarychta K, Mullan B, Luszczynska A: Am I overweight? A longitudinal study on parental and peers weightrelated perceptions on dietary behaviors and weight status among adolescents. Front Psychol 2016; 7:83.

26 Ridder MAM, Heuvelmans MA, Visscher TLS, Seidell JC, Renders CM: We are healthy so we can behave unhealthily: a qualitative study of the health behaviour of Dutch lower vocational students. Health Educ 2010; 110:30-42.

27 Dietz WH, Gortmaker SL: Preventing obesity in children and adolescents. Annu Rev Public Health 2001;22: 337-353.

28 World Health Organization: Global Status Report on Noncommunicable Diseases 2014. Geneva, WHO, 2014.

29 Seidell JC: Epidemiology and health economics of obesity. Medicine 2006;34:506-509.

30 Binkin N, Spinelli A, Baglio G, Lamberti A: What is common becomes normal: the effect of obesity prevalence on maternal perception. Nutr Metab Cardiovasc 2013;23:410-416.

31 Flegal KM, Carroll MD, Kit BK, Ogden CL: Prevalence of obesity and trends in the distribution of body mass index among US adults, 1999-2010. JAMA 2012;307:491-497.

32 Perez Ferrer C, McMunn A, Rivera Dommarco JA, Brunner EJ: Educational inequalities in obesity among Mexican women: time-trends from 1988 to 2012. PLoS One 2014;9:e90195.

33 Barquera S, Campos-Nonato I, Carrión-Rábago C, Villalpando S, López-Ridaura R, Rojas R, et al: Methodology for the analysis of type 2 diabetes, metabolic syndrome and cardiovascular disease risk indicators in the ENSANUT 2006. Salud Publica Mex 2010;52(suppl 1):S4-S10.

34 Breda J, Jewell J, Webber L, Galea G: WHO projections in adults to 2030. Obes Facts 2015;8(suppl 1):18.

35 Keaver L, Webber L, Dee A, Shiely F, Marsh T, Balanda K, Perry IJ: Application of the UK foresight obesity model in Ireland: the health and economic consequences of projected obesity trends in Ireland. PLoS One 2013; 8:e79827.

36 WHO: Constitution of the World Health Organization. 2006. www.who.int/governance/eb/who_constitution en.pdf (last accessed February 1, 2017).

37 Canguilhem G: Le normal et le pathologique, Paris, Presses Universitaires de France, 1943.

38 Huber M. Knottnerus JA, Green L, van der Horst H, Jadad AR, Kromhout D, Leonard B, Lorig K, Loureiro MI, van der Meer JW, Schnabel P, Smith R, van Weel C, Smid H: How should we define health? BMJ 2011;343:d4163.

39 Swinburn B, Egger G. Raza F: Dissecting obesogenic environments: the development and application of a framework for identifying and prioritizing environmental interventions for obesity. Prev Med1999;29:563570. 
Visscher et al.: Perceived Health Status: Is Obesity Perceived as a Risk Factor and Disease?

40 Reaven GM: Role of insulin resistance in human disease. Diabetes 1988; 37:1595-1607.

41 Rissanen A, Heliövaara M, Knekt P, Reunanen A, Aromaa A, Maatela J: Risk of disability and mortality due to overweight in a Finnish population. BMJ 1990;301:835-837.

42 Visscher TLS, Heliövaara M, Picavet HSJ, Rissanen A, Seidell JC: Obesity and musculoskeletal disorders; in Medeiros-Neto G, Halpern A, Bouchard C (eds): Progress in Obesity Research: 9. , Montrouge, John Libbey Eurotext Ltd, 2003, pp 596-603.

43 World Cancer Research Fund, American Institute for Cancer Research: Food, Nutrition, Physical Activity and the Prevention of Cancer: A Global Perspective. Washington DC, American Institute for Cancer Research, 2007. http://discovery.ucl.ac.uk/4841/1/4841.pdf (last accessed February 1, 2017).

44 Kenney El, Gortmaker SL, Davison KK, Bryn Austin S: The academic penalty for gaining weight: a longitudinal, change-in-change analysis of BMI and perceived academic ability in middle school students Int J Obes 2015; 39:1408-1413.

45 McCann C, Roberts RD: Just as smart but not as successful: obese students obtain lower school grades but equivalent test scores to nonobese students. Int J Obes 2013;37:40-46.

46 Fries JF: Aging, natural death, and the compression of morbidity. N Engl J Med 1980;303:130-135.

47 Visscher TLS, Rissanen A, Seidell JC, Heliövaara M, Knekt P, Reunanen A, Aromaa A: Obesity and unhealthy life years in adult Finns. An empirical approach. Arch Intern Med 2004;164:1413-1420.

48 Dhana K, Nano J, Ligthart S, Peeters A, Hofman A, Nusselder W, Dehghan A, Franco OH: Obesity and life expectancy with and without diabetes in adults aged 55 years and older in the Netherlands: a prospective cohort study. PLoS Med 2016;13:e1002086.

49 Sassi F, Cecchini M, Lauer J, Chisholm D: Improving Lifestyles, Tackling Obesity: the Health and Economic Impact of Prevention Strategies. OECD Health Working Paper 48. Paris, OECD, 2009. /www.who.int/choice/ publications/d_OECD_prevention_report.pdf (last accessed February 1, 2017).

50 Cecchini M, Sassi F, Lauer JA, Lee YY, Guajardo-Barron V, Chisholm D: Tackling of unhealthy diets, physical inactivity, and obesity: health effects and cost-effectiveness. Lancet 2010;376:1775-1784.

51 van Wier MF, Lakerveld J, Bot SD, Chinapaw MJ, Nijpels G, van Tulder MW: Economic evaluation of a lifestyle intervention in primary care to prevent type 2 diabetes mellitus and cardiovascular diseases: a randomized controlled trial. BMC Fam Pract 2013;14:45.

52 Peirson L, Fitzpatrick-Lewis D, Morrison K, Ciliska D, Kenny M, Usman Ali M, Raina P: Prevention of overweight and obesity in children and youth: a systematic review and meta-analysis. CMAJ Open 2015;3:E23-E33.

53 Bocca G, Corpeleijn E, Broens J, Stolk RP, Sauer PJ: Dutch healthcare professionals inadequately perceived if three- and four-year-old preschool children were overweight. Acta Paediatr 2016;105:1198-1203.

54 Rollnick S, Butler CC, Kinnersley P, Gregory J, Mash B: Motivational interviewing. BMJ 2010;340:c1900.

55 Miller WR, Rollnick S: Ten things that motivational interviewing is not. Behav Cogn Psychother 2009;37:129140.

56 Miller WR, Rollnick S: Motivational Interviewing: Preparing People for Change. New York, Guilford Press, 2002.

57 Elwyn G, Dehlendorf C, Epstein RM, Marrin K, White J, Frosch DL: Shared decision making and motivational interviewing: achieving patient-centered care across the spectrum of health care problems. Ann Fam Med 2014;12:270-275.

58 Seidell JC, et al: Zorgstandaard Obesitas. Partnerschap Overgewicht Nederland. Amsterdam, 2010.

59 Lissner L, Visscher TLS, Rissanen A, Heitman BL: Monitoring the obesity epidemic into the 21st century weighing the evidence. Obes Facts 2013;6:561-565.

60 Roda C, Charriere H, Feuillet T, Mackenbach JD, Compernolle S, Glonti K, Ben Rebah M, Bárdos H, Rutter H, McKee M, De Bourdeaudhuij I, Brug J, Lakerveld J, Oppert JM: Mismatch between perceived and objectively measured environmental obesogenic features in European neighbourhoods. Obes Rev 2016;17(suppl 1):3141.

61 Popkin BM; Bellagio Meeting group: Bellagio Declaration 2013:countering Big Food's undermining of healthy food policies. Obes Rev 2013;14(suppl 2): 9-10.

62 Butland B, Jebb S, Kopelman P, et al. Foresight Tackling Obesities: Future Choices - Project Report. 2nd ed. London, Government Office for Science, 2007.

63 Popkin B, Monteiro C, Swinburn B: Overview: Bellagio conference on program and policy options for preventing obesity in the low- and middle-income countries. Obes Rev 2013;14(suppl 2):1-8.

64 Pomeranz JL, Brownell K. Portion sizes and beyond - government's legal authority to regulate food-industry practices. N Engl J Med 2012;367:1383-1385.

65 Young LR, Nestle M: The contribution of expanding portion sizes to the US obesity epidemic. Am J Public Health 2002;92:246-249.

66 Duffey KJ, Popkin BM: Energy density, portion size, and eating occasions: contributions to increased energy intake in the United States, 1977-2006. PLoS Med 2011;8:e1001050.

67 Benton D: Portion size: what we know and what we need to know. Crit Rev Food Sci Nutr 2015;55:988-1004.

68 Colapinto CK, Fitzgerald A, Taper J, Veugelers PJ: Children's preference for large portions: prevalence, determinants, and consequences. J Am Diet Assoc 2007;107:1183-1190.

69 Ordabayeva N, Chandon P: In the eye of the beholder: visual biases in package and portion size perceptions. Appetite 2016;103:450-457. 
70 Cairns G, Angus K, Hastings G: The Extent, Nature and Effects of Food Promotion to Children: A Review of the Evidence to December 2008. Geneva, World Health Organization 2009. www.who.int/dietphysicalactivity/ publications/marketing_evidence_2009/en/ (last accessed February 1,2017).

71 Carter OB, Patterson LJ, Donovan RJ, Ewing MT, Roberts CM:. Children's understanding of the selling versus persuasive intent of junk food advertising: implications for regulation. Soc Sci Med 2011;72:962-968.

72 WHO Regional Office for Europe: Prevention and Control of Noncommunicable Diseases in the European Region: A Progress Report. Copenhagen, World Health Organization, 2014.

73 Act CIII of 2011 on the Public Health Product Tax. (copied reference from Global Status Report on Noncommunicable Diseases 2014 by WHO) (in Hungarian). Budapest, Hungarian National Institute for Health and Development, 2013. /www.oefi.hu/NETA_hatasvizsgalat.pdf (last accessed February 1, 2017).

74 Small L, Lane H, Vaughan L, Melnyk B, McBurnett D: A systematic review of the evidence: the effects of portion size manipulation with children and portion education/training interventions on dietary intake with adults. Worldviews Evid Based Nurs 2013;10:69-81. 